\title{
Adapting English for the specific purpose of tourism: A study of communication strategies in face-to-face encounters in a French tourist office
}

L'anglais mis au service de l'échange d'informations touristiques: une étude des stratégies de communication dans des interactions en face-à-face au sein d'un office de tourisme français

\section{Adam Wilson}

\section{(2) OpenEdition}

\section{Journals}

Electronic version

URL: http://journals.openedition.org/asp/5118

DOI: 10.4000/asp.5118

ISSN: 2108-6354

Publisher

Groupe d'étude et de recherche en anglais de spécialité

\section{Printed version}

Date of publication: 1 March 2018

Number of pages: $53-73$

ISSN: 1246-8185

\section{Electronic reference}

Adam Wilson, «Adapting English for the specific purpose of tourism: A study of communication strategies in face-to-face encounters in a French tourist office », ASp [Online], 73 | 2018, Online since 01 March 2019, connection on 02 November 2020. URL : http://journals.openedition.org/asp/5118 ; DOI : https://doi.org/10.4000/asp.5118

This text was automatically generated on 2 November 2020.

Tous droits réservés 


\section{Adapting English for the specific purpose of tourism: A study of communication strategies in face- to-face encounters in a French tourist office}

L'anglais mis au service de l'échange d'informations touristiques: une étude des stratégies de communication dans des interactions en face-à-face au sein d'un office de tourisme français

Adam Wilson

\section{Introduction}

International tourism is one of the biggest industries in the world. According to the United Nations World Tourism Organization, there were 1,235 million international tourist arrivals in 2016 , contributing to an industry worth $\$ 1,220$ billion ( $€ 1,102$ billion) and representing $10 \%$ of the world's GDP (UNWTO 2017). It is also one of the main sources of employment around the world with the UNWTO estimating that 1 in 10 jobs is in some way linked to tourism. As a truly international industry which is both growing and diversifying consistently, tourism has been labeled as one of "the greatest population movements of all time" (Bruner 2005: 10). It is then one of the most diverse, far-reaching and lucrative industries - and employment sectors - in the world.

2 Research from various domains of study that focus on the English language - English for Specific Purposes (ESP), English as a Lingua Franca (ELF) or English as a Foreign Language (EFL) to name but a few - has consistently shown that English is often a key resource in comparable intercultural, or multicultural, industries, often taking on the role of a lingua franca to allow communication between diverse linguistic groups 
(Jenkins et al. 2011). Naturally, work from these domains has also focused on tourism. However, up to present, this work has tended to be uniquely centred on training future professionals through studies of English use in tourism training situations and/or the elaboration of needs analyses for those professionals (Garcia Laborda 2003 or Prachanant 2012, for example). Descriptions of in situ English language use drawn from fieldwork undertaken in contexts of tourism are few and far between.

This is surprising given that tourism, as an ever-diversifying international service industry, places huge importance on intercultural communication skills. These skills are crucial for the elaboration, promotion, delivery and consumption of tourist products, services and experiences. In comparable sectors (such as international student mobility or international business), English plays a vital role and it would seem fair to conclude that the tourism industry could constitute not only a key sector in which English is used in intercultural communication, but also a prime destination for users of ESP or ELF. In short, tourism accounts for one of the most widespread uses of English for a specific purpose - in this case, the specific purpose of conducting the business of tourism. This specialised activity could include welcoming, directing and advising tourists or elaborating the tourist experience by 'framing' tourist destinations and attractions, for example. Despite this, and the potential repercussions of this situation, the role of English and its use remain relatively unexplored in the sector of tourism.

4 This paper aims to take a first, exploratory step into studying in situ English use in a context of international tourism. How do speakers draw on English as a linguistic resource in this context? How is English used to help them co-construct meaning? What are the linguistic features of this specific use of English? In answering these questions, this article aims to contribute to an exploration of the use of English for the specific purpose of tourism. While hoping to build on previous work in ESP, ELF and other fields whilst also providing data and analyses that could be valuable in the elaboration of linguistic training materials for tourism professionals, the nature of this study is exploratory. The aim then is to make an initial attempt at describing English use in this context, thus signalling potential avenues for future research without claiming to provide a definitive account of English use in international tourism.

In the next section, a brief review of relevant literature on both the relationship between language and tourism and English use in intercultural contexts is conducted. Drawing on this review, it is shown how speakers in these contexts employ certain communication strategies in order to construct and ensure understanding. Two of these strategies - repetition and reformulation - are shown to be of particular interest and thus form the basis for this study and its research questions. The fieldwork, data and corpus used in this research are then outlined in section 3. The analysis provided in section 4 shows how speakers employ certain online pragmatic strategies in order to co-construct meaning in this context. The specific roles of repetition and reformulation in this process are explored. Finally, a brief conclusion is drawn before a short presentation of the potential interest of these findings for the ESP domain, both in terms of research and teaching applications, is put forward. 


\section{Language and tourism}

6 In recent years, a hive of activity has developed around the study of tourism in certain branches of the social sciences, and linguistics has been no exception, with work often highlighting the central role that language plays in tourism. For example, a number of researchers have focused on how language is fundamental in elaborating the "tourist gaze" (Urry 1990) - that is, the visual and sensory experiences tourists encounter through the "mise-en-scène" organised by destinations. Thurlow and Jaworski (2010) explore how language and discourse, viewed as semiotic resources, are vital components of the "tourist gaze" described above by showing how they contribute to the elaboration of the tourist experience. Similarly, as language is a key tool in marketing the products, services and experiences offered by a tourist destination, it contributes significantly to the positioning of destinations on the tourist market and, thus, to their image and identity (Heller et al. 2014, among others). In other words, language is vital to the exchange of the intangible, semiotic elements that make up tourism.

7 As well as this semiotic role, language also has huge importance as a more practical tool in tourism situations. As in any service industry, language is essential for conducting most of the business that is undertaken in tourism contexts. Communication between hosts, guests, service providers, locals, businesses and all the other stakeholders involved in tourism requires language use. In this respect, tourism is perhaps an especially interesting case as certain specificities linked to the context create extra challenges for the smooth running of such communication. For example, tourism is not only an extreme example of an intercultural situation (and of language contact) but encounters in this context are also very often "fleeting relationships" (Jaworski \& Thurlow 2010) in that the different participants only spend a very short amount of time in each other's company.

Despite these challenges and the fact that language plays a key role in tourism in both semiotic and practical terms, very little work has been undertaken to study language use in situ in this context. Up to present, studies have tended to focus on written and other mediatised forms of text (Thurlow \& Jaworski 2010, among others). Research focusing on English has also addressed these issues by exploring the stylistic features of English used in different types of tourism texts (Dann 1996; Manca 2008; Bruyèl-olmedo \& Juan-Garau 2010 or Luzón 2016, for example). While this body of work has brought to light how language contributes to the elaboration of the tourist experience, very little is known about how participants in tourism contexts co-construct these experiences together in face-to-face encounters. This article aims to take a first step in addressing this concern by exploring how speakers draw upon certain linguistic resources in situ in order to co-construct meaning.

\section{Pragmatic strategies and English as a lingua franca}

Although little work has been done on tourism in this respect, a large number of studies have shown how English constitutes a key resource for in situ meaning making in comparable situations of intercultural contact. Research focused on English as a lingua franca (ELF) - that is, as a language of communication between speakers from two or more different linguistic groups - in naturally occurring settings has shown how 
speakers develop strategies at different linguistic levels in order to facilitate mutual understanding (Jenkins et al. 2011 for an overview).

One key finding from ELF research focusing on pragmatics has been that speakers seem to give precedence to understanding rather than to the form of what they are saying (Firth 1996, for example). Rather than aiming for 'grammatically correct linguistic forms', speakers of ELF devote energy to developing pragmatic strategies in order to understand others and make themselves understood. These strategies are used to counter both real and potential obstacles that could impede the co-construction of meaning. In other words, speakers prioritise the establishment and maintenance of "common ground" (Stalnaker 2002), that is the presuppositions or knowledge shared by interlocutors concerning, among other things, what is taking place in interaction, the context of the encounter and the objectives or goals of the exchange. Establishing and maintaining this common ground are key to the creation of mutual understanding.

11 Research from different disciplines has identified a large number of strategies that facilitate this process, including clarification (Mauranen 2006), appeals for help (Dörnyei 1995) or code-switching (Cogo 2009) to name but a few. However, the strategy that has received the most attention is that of repetition (Mauranen 2006; Lichtkoppler 2007, and Björkman 2014, among others). For example, building on previous work, Lichtkoppler (2007) explores the various pragmatic functions of repetition such as gaining time, ensuring accuracy of understanding, providing prominence to certain discursive elements or showing listenership. Mauranen (2006) highlights how communicative problems can be managed through the repetition of items that constitute obstacles to understanding. Across a number of studies then, repetition has been shown to be a key strategy allowing speakers to manage understanding (and potential misunderstandings) and thus facilitate the co-construction of meaning in interaction.

12 Another strategy which has been relatively unexplored in ELF research but widely studied elsewhere is that of reformulation. Reformulation, which can be defined as the repetition of information using alternative linguistic forms, is at the heart of Pennec's (2017) corpus-based approach to studying discursive readjustment in English. Similarly, repetition has been the focus of much research in the field of "exolingual communication". Exolingual communication (or communication exolingue) was an extremely active research area in the French-speaking academic world in the 1980s and which focused on similar issues to those found in ELF research. Exolingual communication is defined as communication between speakers who do not (or do not want to) share a first language (Porquier 1979). Studies in this field have examined how the asymmetry of speakers' linguistic repertoires manifests itself in interaction and how speakers overcome this (Alber \& Py 1986). One way in which asymmetry is both manifested and overcome is through exolingual communication strategies, implemented by participants to maximise mutual understanding (Desoutter 2009). A large number of authors have dealt with different strategies which bear a striking resemblance to those explored in ELF research: requests for help (Berthoud \& Py 2003), "semiotic generosity" (Porquier \& Py 2004: 23) or repetition (Schmale 1988), for example. Among the different strategies, reformulation has been shown, as discussed in more detail below, to be particularly powerful in ensuring the co-construction of meaning and can be used as both a preventive measure and a response to a problem in interaction (Alber \& Py 1986; de Pietro 1988). 

is used as a lingua franca have identified the importance of using pragmatic strategies to establish and maintain common ground in order to ensure mutual understanding. Among these strategies, repetition and reformulation seem to play a particularly important role. They are thus central to the co-construction of meaning in such contexts.

Despite the fundamental importance of meaning making in the elaboration of tourist destinations, and the fundamental importance of pragmatic strategies to this process, next to no research has been undertaken which focuses on such strategies in tourism. The aim here will thus be to focus on these strategies in a context of international tourism to show how they constitute one of the ways in which English is exploited as a linguistic resource. In turn, this will show how English is used in situ to co-construct meaning and, by extension, how it contributes to the elaboration of the tourist context. Given the previous research presented above, the role of these strategies in elaborating common ground will clearly be a key concern in exploring these issues. With these elements in mind, the following research questions will be addressed:

- How is common ground established and maintained by participants in face-to-face interactions in a context of international tourism?

- How do participants use pragmatic strategies, and more specifically repetition and reformulation, in this process?

Answering these questions should help shed light on how English is used as a tool for communication in this professional situation, how it contributes to the semiotic elaboration of the context, and how these dynamics may have an effect on the language itself, thus contributing to a provisional outline showing how English is used for the specific purpose of tourism. In order to answer these questions, a corpus of naturally occurring interactions from a context of international tourism was created and is presented in the next section.

\section{Fieldwork and research methodology}

16 In order to answer the research questions set out above, this paper relies on data issued from a long-term ethnographic fieldwork project undertaken between 2014 and 2016. An ethnographic approach was chosen as it draws on an analytical framework which sees language as an intrinsic, constitutive element of its context. In other words, "language is context, it is the architecture of social behaviour itself" (Blommaert \& Jie 2010: 7). From an ESP point of view, such an approach, requiring language to be studied in its naturally occurring context, allows us to analyse English as an intrinsic part of the specific purpose it is being used for and the specific context it is being used in.

17 The context chosen for this study was the Tourist Office and Convention Bureau (TO) of Marseille, France. Marseille is a particularly interesting case for studying tourism as it is currently reinventing itself as an urban tourist destination and international arrivals have been increasing steadily over the past fifteen years (City of Marseille, 2016). This intensification of activity has led to the tourism industry becoming more and more important for the city, and authorities suggest that more than 14,000 jobs are directly or indirectly linked to tourism (for a population of just about a million). 
The TO was chosen as it is one of the key sites in which face-to-face encounters between international tourists and tourism professionals take place. In 2016, 353,144 tourists visited the TO, 56\% of whom came from outside France (City of Marseille, 2016). The fieldwork comprised observations, interviews and document collection as well as recording interactions between international tourists and the French tourist advisers working on the TO's main information desk. This produced a corpus of 93 transcribed and annotated audio recordings of interactions between international tourists and tourist advisers. The data from this corpus, named the Corpus MITo (Wilson, 2016), are the focus of this article. Of the 93 interactions, 26 take place in English. While this constitutes a small corpus, these interactional data provide a valuable snapshot of English being used for the specific purpose of international tourism in face-to-face encounters. Due to the small corpus size, this study focuses on qualitative description of relevant phenomena. Using the tools outlined above, these data are explored with a view to showing how participants use the pragmatic strategies of repetition and reformulation in order to co-construct the common ground, and thus the meaning, required to fulfil the specific purpose in this context, that is, the elaboration of the tourist experience.

\section{Establishing and maintaining common ground at the Tourist Office}

Our analysis focuses on three strategies: online co-construction of utterances, repetition and reformulation. It will be shown how these strategies play an important role in overcoming real and perceived difficulties in communication, thereby protecting said common ground. Together, these findings should constitute a first, exploratory, step towards understanding the use of English for the specific purpose of tourism.

\subsection{Co-construction of utterances}

While repetition and reformulation have been identified above as particularly pertinent pragmatic strategies when establishing common ground, a fine-grained analysis of the corpus reveals another important strategy that plays a similar role. At the discourse level, participants engage in a strategy whereby they collaborate, in real time, to construct utterances. This is what Mauranen (2006: 145) refers to as the "general coconstruction of expressions," sequences in which speakers finish or elaborate upon other speakers' utterances by "pooling relevant factual information." Mauranen focuses on this phenomenon as a strategy for preventing misunderstanding. In the case of the TO, it seems to also have an additional function in allowing participants to show their interlocutor that certain elements of the information being discussed are shared, thus contributing to the elaboration of common ground. This phenomenon can be found in 12 of the 26 interactions in English. Due to space constraints, it is illustrated here through two clear, canonical examples.

21 The first example below is an extract from an interaction between a French tourist adviser (CF7) and a Chinese tourist (T1). The exchange is drawing to a close as T1 opens a new sequence by formulating the request at the beginning of this extract. 
$(1)^{1}$

T1: ok (.) and er one more thing (.) it's just that i know that here is pro- pretty close

to ah cassis (.) and i can see all the euh erm the:

CF7: calanques?

T1: yes calanques yes

CF7: ok

T1: so erm where if $\mathrm{i}$ erm want to book er a boat or something where can $\mathrm{i}$ go and

what are roughly the price for that one common ground regarding Marseille, this is not always the case. The following extract shows how participants use the same strategy in order to establish common ground in terms of the tourist experience more generally. Here, a French adviser (CF4) has just finished presenting the different museums to two tourists, one Vietnamese (T2) and one Italian (T3), when the question of pricing is brought up.

(2)

T3: so what about the museums so it's the::: er so there's no er there's no discount we need to ask for the ticket office

(1.71)

T2: is this discount for students?

CF4: no this exhibition is this (.) er is ten euros (.) this is the most expensive errr ok

(.) after for the mucem this is eight euros

(0.93)

T3: ok maybe there's a discount [for students]

T2: [for students]

CF4: yeah (.) you have to:: (.) yeah you have to show you:::r

T3: yeah yeah yeah

CF4: your student card

T2: how many::: euro discount?

CF4: e::r for mucem it's five euros instead of eight

T3: uhuh

In this case, the main instance of utterance co-construction takes place between T3 and T2. T3 begins to formulate an utterance suggesting that there may be a discount for students which T2 completes (by overlapping T3's original utterance). This clearly displays a sharing of common ground between T2 and T3, no doubt influenced by T2's original reference to student discounts a few turns earlier. CF4 ratifies this collaboration between $\mathrm{T} 2$ and $\mathrm{T} 3$ by offering a reply. However, she quickly signals a 
potential communication problem through two false starts and a reformulation. While this may suggest a word search, T3 immediately ratifies CF4's turn by uttering "yeah yeah yeah" to display understanding. This understanding is ratified by CF4 uttering the words she was looking for, "your student card." This extract shows a clear example of co-construction and collaboration. The participants co-construct the discourse by finishing, or not finishing, each other's turns. This collaboration at the discourse level not only avoids potential obstacles to communication but also contributes to mutual understanding by clearing displaying common ground in terms of a shared comprehension of how pricing functions in most tourist attractions.

The two examples explored above show how the co-construction of utterances contributes to establishing and maintaining common ground at the discourse level. In this way, it constitutes a key strategy in assuring mutual understanding. By extension, this contributes to the discursive construction of certain elements of the tourist context. However, the data suggests that participants cannot rely solely on discourselevel strategies to establish and maintain common ground. More often, this requires the use of certain pragmatic strategies, two of which are discussed in the following sections.

\subsection{Other-repetition}

As mentioned earlier in this article, repetition has been shown to be a key strategy in allowing speakers to co-construct meaning. The aim of this article is to build on this research by exploring data from a relatively unexplored context. This section looks at how speakers at the TO use repetition as a pragmatic strategy to maintain their footing on common ground. Interestingly, self-repetitions are relatively sparse in the corpus. Therefore, the focus here is on other-repetitions, present in all but three of the interactions in the corpus, ${ }^{2}$ and it is shown how the strategic use of other-repetition (OR) can play a number of different roles in the development and protection of mutual understanding.

\subsubsection{Verifying and confirming understanding}

One of the main functions of OR employed by participants in the corpus is related to verifying and confirming understanding. On the one hand, speakers use repetition to check either their own understanding or that of their interlocutor. On the other hand, OR is also used to affirm an interlocutor's or one's own understanding following a potential obstacle to interaction. Both of these strategies are explored in the examples below.

This first example shows how $\mathrm{OR}$ is used by participants to check their own understanding. This extract features a German-speaking Swiss tourist (T4) interacting with a French-speaking adviser (CF1). They are discussing different attractions suitable for children before $\mathrm{T} 4$ asks about buying transport tickets.

(3)

CF1: there is a lot of errm (1.1) er (.) pai- er games=

T4: =yep

CF1: for the kids

T4: ahhh ok=

CF1: =and they have errr the-=

$\mathrm{T} 4:=\mathrm{kay}=$ 


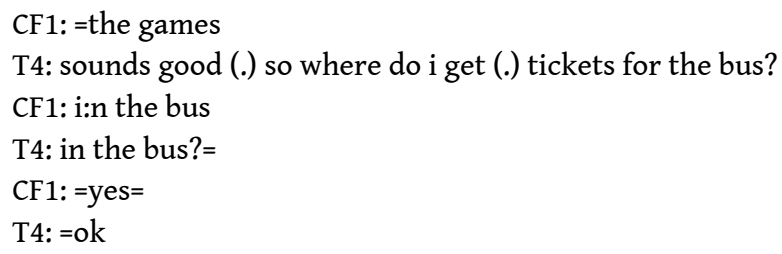
utterance is repeated verbatim by $\mathrm{T} 4$ with a rising intonation. CF1 interprets this repetition as a confirmation request in terms of understanding, which she ratifies in the following turn. The fact that $\mathrm{T} 4$, in turn, produces a ratification suggests that his initial repetition of "in the bus" was indeed an attempt to confirm his understanding of CF1's turn. Here then, OR is used strategically by a speaker to check his own understanding, thereby avoiding potential communication roadblocks and maintaining the common ground. Such use of OR has also been reported by Lichtkoppler (2007: 56) who termed this function "ensuring accuracy of understanding" when describing ELF interactions in a university international accommodation office. It is interesting to note that such findings from a different context are reproduced in the context of international tourism.

The following example shows a similar strategic use of OR. However, in this case, rather than acting as verification, the multiple repetitions seem to constitute explicit confirmations of understanding. This extract is taken from an interaction between a French adviser (CF7) and a Japanese tourist (T5). CF7 is explaining how to get to a major tourist attraction using public transport.

(4)

CF7: or you can go (.) by bus with the bus number sixty

T5: ok (.) just nearby it's not far

CF7: yeah and you buy the ticket inside the bus

T5: inside the bus

CF7: and it's one eighty euro

T5: one eighty (.) but if i buy (.) previously it's just like one fifty (.) or no

CF7: if you buy in metro

T5: yes

CF7: if you go in the metro and you buy a ticket it's one fifty

T5: one fifty ok

CF7: yeah

There are three instances of OR is this extract, all of which seem to play the same role T5's productions of "inside the bus", "one eighty" and "one fifty" are all verbatim repetitions of CF7's previous turn (or a part of said turn). These examples of OR seem to act like positive feedback, signalling understanding. They are never interpreted otherwise - as clarification requests or signals of incomprehension, for example - by CF7. Similarly, T5 does not manifest any sign that would suggest that these ORs be interpreted in another way. This use of OR as positive feedback confirming understanding is widespread throughout the corpus. Used in this way, OR constitutes a strategy allowing participants to signal the continuing existence of common ground between them.

The strategic uses of OR to both verify and confirm understanding can be seen in the following extract. It is taken from the same interaction as in example (2). Here, the tourists are asking about the different buildings which can be visited in Marseille when 
T2 asks about one of Marseille's most famous landmarks, Le Corbusier (or Cité Radieuse).

(5)

T2: how about the area of err le corbusier?=

T3: =le corbusier?

0.80 )

CF4: corbusier (.) it's (.) here

T3: cité:: radieuse

CF4: you have to take the bus number twenty one

T3: ok

The first OR takes place when T3 repeats the name "Le Corbusier" in response to T2's initial interrogation. Coupled with a rising intonation, this acts as a verification on the part of T3 to verify his understanding of T2's production. The second OR takes place when CF4 repeats “Corbusier" to ratify T3's comprehension of T2's utterance. Though the audio data is not presented here, it is worth noting that there is no notable difference in the pronunciation of "Corbusier" between the three speakers. It would therefore seem difficult to argue that these repetitions constitute reformulations, repairs or corrections in terms of pronunciation. This suggests that OR plays a pragmatic role, allowing certain speakers to verify understanding and others to confirm that understanding. This protects the common ground, ensuring a smooth elaboration of mutual understanding.

\subsubsection{Signalling and repairing misunderstanding}

Alongside verifying and confirming understanding, analysis of the corpus shows that OR has a second major strategic use among visitors and advisers at the TO: signalling and repairing obstacles to understanding. As mentioned previously, Mauranen (2006: 133) shows how misunderstanding can be signalled through the "repetition of problematic items." This phenomenon, observed by Mauranen in ELF data from a higher education situation, can also be found in the present corpus. Once again then, phenomena observed in other ELF contexts can be found in international tourism. The extract below provides a good example.

(6)

T6: do you have some maps of the campings?

(.)

CF8: maps of the campings?

T6: yes

CF8: e::r

T7: in france

T6: in this region

CF8: ah this region (.) je pense i don't think so but i'm going to see

This extract is from an interaction between two Portuguese tourists (T6, T7) and a French tourist adviser (CF8). T6's initial request comes after a long break in the interaction in which CF8 was searching for documentation. CF8 repeats the final part of T6's utterance with a rising intonation. Initially, T6 seems to interpret this repetition as a confirmation of understanding. However, when T6 ratifies this confirmation, CF8 gives feedback suggesting a breakdown in understanding, prompting reformulations from both T7 and T6. It seems then that CF8's repetition of "maps of the campings" is not a confirmation of understanding but rather a repetition of an element that constitutes an obstacle to comprehension. Thus, CF8 uses repetition as a strategy to 
signal misunderstanding, that is, a temporary loss of common ground between the participants. Interestingly, CF8 also signals the return of said common ground through the use of OR. In the final turn above, she repeats part of T6's previous utterance. This clearly acts as a ratification of understanding. It can be seen then how OR is used to both signal misunderstanding and resolve such problems.

The following extract provides an example of very similar usage of the same strategy. In this exchange between a Japanese tourist (T8) and a French adviser (CF1), OR is used to both signal and repair misunderstanding. The interaction is drawing to a close and CF1 is explaining the "Citypass," a card offering reductions for certain attractions, when $\mathrm{T} 8$ decides to buy one of the products on offer.

(7)

CF1: and you have some er reduction in (.) some shops

T8: $\mathrm{mmhmm}$

T8: ok i want a two- two days pass

CF1: yes (1.2) one citypass for two days.

T8: on::e?=

CF1: =>one citypass<

T8: ah one citypass yes

The repetitions appear at a crucial moment in the transaction. Following CF1's recapitulation of the product being sold, T8 repeats one of the crucial elements of information: "one." This repetition, accompanied by a rising intonation, seems to be interpreted by CF1 as signalling misunderstanding. In response, CF1 repeats (and simplifies) her utterance. This instance of repetition acts to resolve the misunderstanding. T8 then confirms her understanding through the use of another OR. Repetitions are used here to signal a risk to the common ground, to propose a solution leading to its re-establishment and to ratify this solution, thereby re-establishing the common ground.

\subsubsection{Other-repetition as a feature of English use in tourism}

Following the analyses of the corpus presented here, four strategic functions of OR can be identified: verifying understanding, confirming understanding, signalling misunderstanding and repairing misunderstanding. Clearly then, OR constitutes a powerful strategy in terms of establishing and maintaining common ground between participants. It therefore plays a fundamental role in the co-construction of meaning and mutual understanding in this context.

39 As mentioned above, these conclusions largely echo research findings from other ELF situations in that $\mathrm{OR}$ constitutes a clear characteristic of the English (as a lingua franca) used in the context of the TO. While this may not be surprising, international tourism remains a relatively unexplored context in terms of ELF and it is interesting to note the existence of phenomena comparable with other contexts, despite the fact that the defining characteristics of these situations may be somewhat different (see section 1). If, based on this evidence, OR is to be considered as a pragmatic feature of in situ English use in a context of international tourism, it could be suggested that OR constitutes a feature of English used for the specific purpose of tourism. In contributing to the maintenance of common ground, OR contributes not only to mutual understanding between participants but also to the discursive and semiotic creation of the tourist context. This happens on two levels. Practically speaking, OR helps to 
ensure the transmission of directions or advice that will shape a tourist's actual experience in Marseille. Discursively speaking, OR ensures that the semiotic constructions of tourism are communicated in the encounters between tourists and advisers.

OR clearly constitutes a key feature, and strategy, of English use in tourism. However, another feature can be identified through the analyses of the corpus collected at the TO: reformulation.

\subsection{Reformulation}

41 As with repetition, qualitative analysis of the corpus reveals reformulation to be of strategic importance to speakers at the TO. While reformulation is briefly referred to as a common "corrective device" in situations of English learning by Jenkins (2012: 490), its strategic function has been explored to a lesser extent in work focusing on ELF. Research in the field of exolingual communication has studied the role of reformulation as a key strategy in ensuring mutual understanding (de Pietro 1988). Authors from this field distinguish reformulation within the same language (by selecting alternative forms when "repeating" information) from reformulation through the temporary use of another language or variety (Alber \& Py 1986). Both forms of reformulation are widespread in the present corpus, appearing in 20 of the 26 interactions, and are explored through the canonical examples below. It is shown how, in much the same way as OR, different forms of reformulation contribute to the maintenance of common ground between speakers, thereby contributing to the coconstruction of meaning.

\subsubsection{Intra-code reformulation}

42 The first form of reformulation that is considered can be termed "intra-code reformulation" i.e. reformulation which takes place in the same language. In this first extract, an American tourist (T9) has just asked about the boat trips (to the Frioul islands) available with the "Citypass" tourist pass she has bought online. The French adviser (CF6) explains that T9 must make a choice between the two trips advertised online. This leads to a series of reformulations that function as a pragmatic strategy to ensure understanding between the participants, protecting the common ground.

(8)

T9: ok

CF6: or to le frioul (.) so it's ONE or the other one you have to choose (.) so this is a timetable (.) leaflet for if castle (.) and information for the island of frioul?

T9: ok so choose between these two?

CF6: yeah if you want to do both (.) you have to pay an extra five euros

T9: ok

First of all, CF6 self-initiates a reformulation by uttering "one or the other" followed by "you have to choose." This particular grammatical construction could be considered as somewhat difficult, especially when the differences between the various forms in English and French (CF6's first language) are taken into account. Bearing this in mind, it could be suggested that CF6 reformulates her own utterances as a preventive strategy to avoid potential misunderstanding. In the following turn, $\mathrm{T} 9$ reformulates this construction by adding "between these two." This seems to be interpreted by CF6 as a request for clarification, which she responds to by reformulating the proposition one 
more time and adding extra information. In this extract, reformulation acts in a number of strategic ways: preventing potential misunderstanding, requesting clarification and responding to communicative difficulties. Together, these three strategic uses of reformulation help the interlocutors to maintain common ground.

The following extract shows a way in which strategic reformulation can help not only maintain common ground but also actively establish it. This example features two Irish tourists $(\mathrm{T} 10, \mathrm{~T} 11)$ exchanging with a French adviser (CF8) about the tourist buses that tour the city.

(9)

CF8 if you want to e::rm (.) to go up or go down

T10 a:::h

CF8 it's possible you have (.) several (.) stops

T10 ahhh

T11 ok

CF8 you ca:::n stop here if you want uh (.) it's a little port with a restaurant typically err o- of marseille

T10 mmhmm

CF8 and er um and after you you have to take this bus (.) you find find o:h and you have the timetable here

T10 o:::h so it's hop on hop off=

$\mathrm{CF} 8$ =hop on hop off yes

T10 ok

T11 ok

In much the same way as in the previous example, the adviser (CF8) initiates a selfreformulation. Her reformulation of "to go up or go down" seems to be a done in response to T10's ambiguous feedback. T10 and T11's feedback to CF8's reformulation "it's possible you have several stops" appears to suggest that the potential obstacle to communication has been avoided. At this point, it seems that common ground has been maintained and CF8 continues by giving more information. However, upon seeing the timetable handed to them by $\mathrm{CF} 8$, T10 once again reformulates CF8's initial utterance by using the construction "hop on hop off." This reformulation appears to suggest that the common ground was not fully restored following CF8's first reformulation attempt. However, T10 immediately brings the exchange back on track with her reformulation "hop on hop off" (the phrase used on the printed timetable she has just had handed to her). This is immediately ratified by CF8 through the use of a strategic OR, and the common ground is restored. In this example, reformulation acts as a strategy for repairing obstacles to the co-construction of meaning, to the point of reinstating common ground that had been temporarily lost.

The above extracts contain examples of both self-reformulation and otherreformulation used as pragmatic strategies to facilitate mutual understanding through the protection of common ground. In each of these cases, the reformulation is "intracode" in that the problematic items are reformulated in the same language (English). Attention now turns to reformulations involving elements of languages other than English.

\subsubsection{Inter-code reformulation}

The second type of reformulation under study is "inter-code reformulation", which involves using linguistic resources from languages other than English. Alber and Py (1986) were among the first to identify the contribution of reformulations using 
elements of another language (or code) to meaning making in their work on mainly French-language exolingual interactions. More recently, Mondada and Nussbaum (2012) explored a variety of different situations of language contact to show how speakers exploit various plurilingual resources in order to make themselves understood in a process they term "linguistic bricolage." Among other conclusions, their analyses showed how speakers react to and solve communicative problems online through the use of resources which are not part of the main language of interaction. Regarding ELF, Hülmbauer (2009) discussed the role of plurilingual resources in both the "correctness" and "effectiveness" of ELF as a language variety among international students.

In the case of the TO, inter-code reformulations constitute a clear pragmatic strategy in English-language interactions. While multiple cases cannot be studied due to space constraints, the following extract provides a canonical example of inter-code reformulation at the TO. In this encounter, two Spanish tourists (T12, T13) are engaged in an interaction with a French adviser (CF1) when T12 asks a question about one of Marseille's most famous products: soap.

(10)

T12: about (.) there is some e:::: /sup/ /i/ /supi/ /fæbriki/?

(1.1)

T12: /sup/?

CF1: /sup/?

T12: /marselsups/

(1.4)

T12: /sabon/ [/sabo/- ]

T13: [soap ]

CF1: savon.

T12: ah savon

(0.7)

CF1: /sabon/ no i don't understand

(1.2)

T13: a soap (.) to wash (.) a soap

CF1: AH YES savon=

T2: =euheuh

CF1: yes (.) so (.) if you want (.) in this street

49 As can be seen, T12 runs into some difficulty with the pronunciation of "soap." Her initial turn leads to an absence of feedback, so T12 repeats the same pronunciation. In a strategic use of repetition, CF1 signals her incomprehension by reproducing the same form. T12 adds information but this leads to another lack of feedback. Interpreting this as incomprehension, T12 reformulates the problematic element with the production "/ sabon/" which sits somewhere between the French (savon) and Spanish (jabón) versions of this lexical item. Simultaneously, T13 reformulates soap with a more "native-like" pronunciation but this seems to go unheard. Despite initially seeming to ratify the reformulation by repeating the French word "savon", CF1 goes on to explicitly express her incomprehension. T13 then reformulates "soap" once again, leading to CF1's ratification through the use of an inter-code reformulation by employing the word " savon".

It is clear that T12's inter-code reformulation is used in a strategic manner with a view to resolving misunderstanding. This example - one of a number in the corpus - shows how reformulation using linguistic resources from another language constitutes a 
pragmatic strategy speakers exploit (or attempt to exploit) in order to maintain common ground and thus mutual understanding.

\subsubsection{Reformulation as a feature of English use in tourism}

51 The exploration of the above examples reveals certain strategic uses of reformulation in the corpus of English-language interactions between tourists and advisers at the TO of Marseille. Firstly, reformulation can either be "intra-code" or "inter-code," relating to the exploitation of another English form or resources from another language respectively. It has also been shown that participants can either self-reformulate or other-reformulate. All of the aforementioned forms of reformulation play a strategic role. The pragmatic functions enacted by reformulation include requesting clarification and anticipating or repairing obstacles to understanding. By doing so, reformulation contributes considerably to the establishment and maintenance of common ground. In much the same way as repetition, reformulation proves to be a key strategy in the coconstruction of meaning between participants in this context.

Given its strategic importance, it could be argued that reformulation constitutes a characteristic of the English used (as a lingua franca) in this context and, by extension, a feature of English used for the specific purpose of tourism. Strategic intra-code and inter-code reformulations contribute to mutual meaning making and thus to the linguistic elaboration of the tourist context. As with OR, reformulation is a key feature and strategy of English use in tourism based on the evidence presented here.

\section{Conclusion}

The main aim of this article was to take an initial, exploratory step towards studying the in situ use of English in a context of international tourism. This was done through close analysis of interactional data from an ethnographic fieldwork project undertaken at the tourist office of Marseille (TO). Focus was given to English being used as a lingua franca in encounters between (certain) international tourists and tourist advisers. The objective of this paper was to explore how the speakers exploit linguistic resources in order to co-construct meaning. By focusing on the elaboration and maintenance of common ground, it was shown that speakers activate certain strategies in order to facilitate this meaning making process. Three strategies were identified as being particularly prominent: co-construction of utterances, repetition and reformulation. Firstly, participants engage in the co-construction of utterances by collaborating in real time through the pooling of linguistic resources and information in order to elaborate utterances. This strategy, operating at the discursive level, allows participants to establish common ground by displaying shared information. Secondly, it was shown how speakers utilise repetition as a pragmatic strategy that can have various functions. According to the data, repetition is used to verify and/or confirm understanding as well as to signal and/or repair misunderstanding. Finally, reformulation was also shown to play a similar pragmatic role by allowing speakers to request clarification as well as to anticipate or repair communicative difficulties. All three of these strategies were shown to play an important part in establishing and maintaining common ground between the speakers which is central to ensuring mutual understanding. The discursive and pragmatic strategies exposed in this article are thus shown to be key resources for the co-construction of meaning that takes place between speakers in this 
context. By extension, these strategies contribute to the elaboration of the tourist experience itself, either through ensuring the smooth communication of practical details that will form the basis of a tourist's visit to Marseille or by facilitating the semiotic construction that constitutes an integral part of the tourist experience.

This final conclusion is particularly important as it shows how English can be used for a specific purpose in this context. In other words, speakers at the tourist office draw upon English for the specific purpose of tourism, both in terms of its practical organisation and its semiotic elaboration. English can therefore be said to constitute a set of linguistic resources that allows this specific purpose to be enacted, thus allowing the elaboration of the particular context. What is more, the analyses presented here would suggest that, in this case, the English used for this specific purpose has specific linguistic features: the three discursive and pragmatic strategies identified above. As mentioned in the analyses above, these strategies in many ways closely resemble those found in other ELF/ESP contexts, whilst also presenting certain differences. They are no doubt only the tip of the iceberg and more research is required in order to uncover further strategies and/or other linguistic features of English used as a lingua franca in international tourism. However, as in other contexts of ESP, this study has provided an initial sketch as to how English becomes an integral part of the specific purpose tourism - for which it is being used. The evidence presented here takes an initial step in showing how English can be considered to contribute to the undertaking of international tourism as well as showing how its being used in this context produces certain linguistic forms. Thus, in this case, English and its specific purpose become somewhat inseparable; language and context become one.

The above conclusions could be important not only for future research in ESP but also for its applications in terms of training and education. In much the same way as in a needs analysis, the elements explored here give initial insight into the requirements of tourism professionals (and tourists, for that matter) in terms of English language skills. The discursive and pragmatic strategies laid out in this paper would constitute such skills, suggesting that these skills should form part of the linguistic training of professionals in this sector. While this is undoubtedly the case in a wide range of training and/or language-learning situations, not all programmes incorporate such pragmatic or discursive elements. Clearly, more research is required before any measures are taken to implement such elements in training programmes in order to confirm the findings of this paper and identify other linguistic features of English used for the specific purpose of tourism. However, given that the findings presented here mirror those of other ESP/ELF studies, it could be suggested that there is a growing body of research pointing to the importance of such pragmatic and discursive elements in the language learning or training process, hence their increasingly central role in language learning and teaching.

56 In sum, this paper offers only a very first step towards describing English use for the specific purpose of tourism. However, the conclusions drawn here suggest that more research would be of profound interest for ESP scholars both from a scientific and applied perspective. As discussed in the analysis, the phenomena described here are in some ways very similar to those found in other situations of ESP/EFL whilst there are also some differences in the way English is used in such situations and in this small corpus. It would seem then that exploring English use in tourism could enrich the study of how English is used for a specific purpose and how a specific purpose can have an 
impact on English. In fact, given the significance of tourism as a social phenomenon, the impact of such work could go far beyond this, potentially unveiling central aspects of the influence language can have on society and society can have on language.

ALBER, Jean-Luc \& Bernard PY. 1986. "Vers un modèle exolingue de la communication interculturelle: interparole, coopération et conversation". Études de Linguistique Appliquée 61, 7890.

BERTHOUD, Anne-Claude \& Bernard Py. 1993. Des linguistes et des enseignants: maîtrise et acquisition des langues secondes. Bern: Peter Lang.

BJ̈̈RKMAN, Beyza. 2014. "An analysis of polyadic English as a lingua franca (ELF) speech: A communicative strategies framework". Journal of Pragmatics 66, 122-138.

BLOMMAERT, Jan. \& Dong JIE. 2010. Ethnographic Fieldwork. A Beginner's Guide. Bristol: Multilingual Matters.

BRUNER, Edward. M. 2005. Culture on Tour: Ethnographies of Travel. Chicago: University of Chicago Press.

BRUYÈL-OLMEDO, Antonio \& Maria JUAN-GARAU. 2009. "English as a lingua franca in the linguistic landscape of the multilingual resort of S'Arenal in Mallorca". International Journal of Multilingualism, 6/4, 386-411.

City of Marseille. 2016. Marseille Tourism Observatory: Key Figures 2016. Marseille: City of Marseille. Retrieved from <http://fr.calameo.com/read/002243401dbcd0c813eeb> on 30/09/2017.

COGO, Alessia. 2009. "Accommodating difference in ELF Conversations: A study of pragmatic strategies". In MAURANEN, A. \& E. RANTA, English as a Lingua Franca: Studies and Findings. Cambridge: Cambridge Scholars Press, 254-273.

DANN, Graham. 1996. The Language of Tourism: A Sociolinguistic Perspective. Wallingford: CAB International.

DE PIETRO, Jean-François. 1988. "Conversations exolingues. Une approche linguistique des interactions interculturelles". In COSNIER, J., GELAS, N. \& C. KERBRAT-ORECCHIONI, Echanges sur la conversation. Paris: Éditions du CNRS, 251-268.

DESOUTTER, Cécile. 2009. "Jeu de faces et jeu de places dans les interactions exolingues en entreprise". Synergies Italie, 5, 29-38.

DÖRNYEI, Zoltán. 1995. "On the teachability of communication strategies". TESOL Quarterly, 29/1, $55-85$.

FIRTH, Alan. 1996. "The discursive accomplishment of normality: On 'lingua franca' English and conversation analysis". Journal of Pragmatics, 26/2, 237-259.

GARCIA LABORDA, Jesus. 2003. "Travel and tourism students' needs in Valencia (Spain): Meeting their professional requirements in the ESP classroom". ESP World, 2/5.

HELLER, Monica, Joan PUJOLAR \& Alexandre DUCHÊNE. 2014. "Linguistic commodification in tourism". Journal of Sociolinguistics 18/4, 539-566.

HÜLMBAUER, Cornelia. 2009. "'We don't take the right way. We just take the way that we think you will understand' - The shifting relationship between correctness and effectiveness in ELF". In MAURANEN, A. \& E. RANTA, English as a Lingua Franca: Studies and Findings. Cambridge: Cambridge Scholars Press, 323-347. 
JAWORSKI, Adam \& Crispin THURLOW. 2010. "Language and the globalizing habitus of tourism: Toward a sociolinguistics of fleeting relationships". In COUPLAND, N., The Handbook of Language and Globalization. Chichester: Wiley-Blackwell, 255-286.

JENKINS, Jennifer. 2012. "English as a Lingua Franca from the classroom to the classroom". ELT Journal, 66/4, 486-494.

JENKINS, Jennifer, Alessia COGO \& Martin DEWEY. 2011. "Review of developments in research into English as a lingua franca". Language Teaching 44/3, 281-315.

LichtKoppler, Julia. 2007. "'Male. Male.' -- 'Male?' -- The sex is male. “The role of repetition in English as a lingua franca conversations"". Vienna English Working Papers 16/1, 39-65.

LUZÓN, María-José. 2016. "Features of ELF interactions in travel blogs: Travelers doing interactional work". Ibérica 31, 127-148.

MANCA, Elena. 2008. "From phraseology to culture. Qualifying adjectives in the language of tourism". International Journal of Corpus Linguistics 13/3, 368-385.

MAURANEN, Anna. 2006. "Signaling and preventing misunderstanding in English as lingua franca communication". International Journal of the Sociology of Language 177, 123-150.

MONDADA, Lorenza \& Luci NUSSBAUM. 2012. Interactions cosmopolites: L'organisation de la participation plurilingue. Limoges: Lambert-Lucas.

PENNEC, Blandine. 2017. Réajustement(s) du discours en anglais contemporain. London: ISTE Editions.

PORQUIER, Rémy. 1979. "Stratégies de communication en langue non maternelle". Travaux Du Centre de Recherches Sémiologiques, Université de Neuchâtel 33, 39-52.

PORQUIER, Rémy \& Bernard PY. 2004. Apprentissage d'une langue étrangère: contextes et discours. Paris: Didier Scolaire.

PRACHANANT, Nawamin. 2012. "Needs analysis on English language use in tourism industry". Procedia - Social and Behavioral Sciences 66, 117-125.

SCHMALE, Günter. 1988. "Situations de contact ou situations de crise? Activités de figuration dans des communication exolingues". In COSNIER, J., N. GELAS \& C. KERBRAT-ORECCHIONI, Echanges sur la conversation. Paris: Éditions du CNRS, 285-300.

STALNAKER, Robert. 2002. "Common ground". Linguistics and Philosophy 25/5-6, 701-721.

THURLOW, Crispin \& Adam JAWORSKI. 2010. Tourism Discourse - Language and Global Mobility. Basingstoke: Palgrave Macmillan.

UNWTO. 2017. UNTWO Tourism Highlights. 2017 Edition. United Nations World Tourism Organisation, retrieved from <http://www.e-unwto.org/doi/book/10.18111/9789284419029> on $30 / 09 / 2017$.

URRY, John. 1990. The Tourist Gaze. London: SAGE.

WILSON, Adam. 2016. "Dynamiques sociolinguistiques de la globalisation: l'exemple de l'Office du Tourisme de Marseille”. Unpublished PhD thesis. Aix-Marseille Université, Aix-en-Provence, France. 


\section{APPENDIXES}

\section{Transcription conventions}

(1.1) Pause (in seconds)

(.) Short pause

: Prolongation

- False start/interruption

? Rising intonation

[] Overlapping speech

= Speech in quick succession

> Slower speech

ONE Loud speech

// Phonetic transcription

Note: Given that upper-case letters are used to identify loud speech, lower-case letters are used for all other speech, even where graphic conventions would require a capital letter (such as in the use of proper nouns). An effort is made to transcribe each utterance as closely as possible. Therefore, any "non-standard" or "erroneous" English constructions or forms are reproduced as uttered. Similarly, any "filler" or "hesitation" noises are transcribed in order to be as close as possible to the sounds produced by the speakers.

\section{NOTES}

1. See the Appendix for a guide to the transcription conventions used throughout.

2. It should be noted that the three interactions without any other-repetitions are extremely short (under 15 seconds).

\section{ABSTRACTS}

This article explores some uses of English for international tourism. Tourism is one of the biggest industries in the world, yet little work has focused on how non-native speakers use English in face-to-face encounters in this context. This paper studies how speakers co-construct meaning in English through an analysis of interactional data drawn from an ethnographic fieldwork project undertaken at the tourist office of Marseille (France). It is shown how speakers deploy certain discursive and pragmatic strategies in order to elaborate and maintain the common ground necessary for mutual understanding. Three strategies are identified as being particularly prominent: co-construction of utterances, repetition and reformulation. It is shown how these strategies contribute not only to the co-construction of meaning but also to the practical and semiotic elaboration of the tourist experience. These findings are then briefly applied to the field of ESP research and teaching. 
L'objectif de cet article est de proposer un premier pas vers l'étude de l'anglais du tourisme international. Le tourisme constitue l'une des plus grandes industries du monde mais l'exploitation de l'anglais par des locuteurs non-natifs dans des interactions en face-à-face dans ce contexte reste relativement peu explorée. Cet article vise à montrer comment les locuteurs coconstruisent du sens en anglais. Ce travail s'appuie sur l'analyse de données interactionnelles issues d'un travail de terrain ethnographique entrepris à l'office de tourisme et des congrès de Marseille (France). Il apparaît que les locuteurs emploient certaines stratégies discursives et pragmatiques afin d'élaborer un terrain d'entente nécessaire pour l'intercompréhension. Trois stratégies dominent - la co-construction d'énoncés, la répétition et la reformulation - et elles contribuent en outre à la co-construction du sens et à l'élaboration pratique et sémiotique de l'expérience touristique. Ces résultats sont enfin appliqués à la recherche en anglais de spécialité et à de possibles applications pédagogiques.

\section{INDEX}

Keywords: communication strategy, English for tourism, interaction in English, pragmatics Mots-clés: anglais du tourisme, interaction, pragmatique, stratégie de communication

\section{AUTHOR}

\section{ADAM WILSON}

Adam Wilson is currently maître de langue in the Département d'études du monde anglophone (DEMA) at Aix-Marseille University and affiliated with the Laboratoire Parole et Langue (LPL UMR 7309). He defended his PhD thesis, dealing with the sociolinguistic dynamics of globalisation, in 2016. His on-going research continues his work on this theme by focussing especially on language use in tourism. adam.wilson@lpl-aix.fr 